I N S T I T U T O

$\mathrm{DE}$

M E D I C I N A

T R O P I C A L

DE

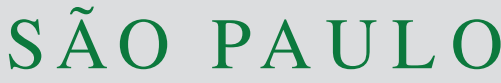

JOURNAL OF THE SÃO PAULO INSTITUTE OF TROPICAL MEDICINE

1 Universidade Federal de Pernambuco, Departamento de Histologia e Embriologia, Recife, Pernambuco, Brazil

${ }^{2}$ Universidade Federal de Pernambuco, Departamento de Medicina Tropical, Recife, Pernambuco, Brazil

${ }^{3} \mathrm{FIOCRUZ}$, Instituto Aggeu Magalhães, Recife, Pernambuco, Brazil

${ }^{4}$ Universidade Federal de Pernambuco, Departamento Materno Infantil, Recife, Pernambuco, Brazil

${ }^{5}$ Hospital Esperança, Recife, Pernambuco, Brazil

${ }^{6}$ Bioimagem Diagnósticos, Recife,

Pernambuco, Brazil

${ }^{7}$ Universidade Federal de Pernambuco, Centro de Ciências Médicas, Recife, Pernambuco, Brazil

${ }^{8}$ Universidade Federal de Pernambuco, Departamento de Fisiologia e Bioquímica, Recife, Pernambuco, Brazil

Correspondence to: Carina Scanoni Maia Universidade Federal de Pernambuco, Departamento de Histologia e Embriologia, Av. da Engenharia, CEP 50730-120, Recife, PE, Brazil

E-mail: carina.scanoni@gmail.com

Received: 4 January 2021

Accepted: 25 March 2021

\section{Treatment of mycobacteriosis in a patient with compatible symptoms after a cesarean delivery}

\author{
Carina Scanoni Maia ${ }^{(1)}$, Paulo Sérgio Ramos de Araújo ${ }^{\left({ }^{2}, 3\right.}$, Haiana \\ Charifker Schindler ${ }^{(1,4}$, Jardel Pereira Soares ${ }^{(5}$, Ana Sofia Cruz ${ }^{(1)} 6$, \\ José Reginaldo Alves de Queiroz Júnior ${ }^{(7}$, Fernanda das Chagas Angelo \\ Mendes Tenorio ${ }^{(1}$, Juliana Pinto de Medeiros ${ }^{\left({ }^{1}\right.}$, , Bruno Mendes Tenorio ${ }^{\left({ }^{1}\right.}$, \\ Gyl Everson de Souza Maciel ${ }^{\circledR 8}$, Rosa Valéria da Silva Amorim ${ }^{\circledR 1}$, \\ Sylvia Lemos Hinrichsen ${ }^{(1)}$
}

\section{ABSTRACT}

This study aims to report the diagnostic course and treatment of a fast-growing mycobacteria infection after cesarean delivery. We report the case of a 37-year-old woman admitted to the Infectious Diseases' Clinic of the Hospital das Clinicas da Universidade Federal de Pernambuco, Pernambuco State, Brazil, four months after a cesarean section, presenting with healing difficulties and located pain outside the surgical site. The first diagnosis was a probable rejection of the sutures that were not absorbed, but based on the clinical signs, reported history, complementary laboratory tests and no response to treatment with the conventional antibiotic therapy (cephalosporins/quinolones) prescribed, the ultimate diagnosis was a mycobacteriosis caused by Micobacterium fortuitum. Since fast-growing mycobacteria do not easily penetrate host tissues, they is mainly related to post-trauma or post-surgical procedures. It is extremely important to call attention to these occurrences in the gynecological-obsthetric field. Treatment for mycobacteriosis is often complicated because of the side effects of antibiotics, especially the ototoxicity of amikacin.

KEYWORDS: Mycobacteriosis. Cesarean. Complication. Treatment.

\section{INTRODUCTION}

Fast-growing mycobacteria (FGM) or mycobacteria non-tuberculous (MNT), have emerged as important human pathogens causing a variety of illnesses, such as post-traumatic infections and post-surgical disseminated skin diseases. These mycobacteria are widely spread in the environment, mainly in water. These microorganisms can contaminate medical equipment and have been responsible for several outbreaks of healthcare-associated infections ${ }^{1}$, but so far, there is no evidence of person-to-person transmission² ${ }^{2}$.

Their occurrence has been frequently reported in surgeries of aesthetic procedures, but also in videolaparoscopies ${ }^{3}$ and secondary to the use of catheters ${ }^{4}$. The nosocomial outbreaks recorded in Brazil are related to failures in cleaning processes of medical products 5 .

The prevalence of FGM infection is increasingly common in clinical practice and might be related to immune system deficiencies ${ }^{2}$. When it comes to the extrapulmonary disease, skin and subcutaneous tissue infections are commonly caused by other types of mycobacterium ${ }^{1,6}$. 


\section{CASE DESCRIPTION}

We report the case of a 37 years old woman who sought the Infectious and Parasitic Diseases (IPD) Clinic, Hospital das Clinicas (HC), Universidade Federal de Pernambuco (UFPE), Pernambuco State, Brazil, four months after a caesarean section, presenting with difficulties in healing and local pain outside the surgical site.

She reported severe pain during the first month after surgery in a hardened palpation area, above the surgical incision, and on the right side of her pelvis. The obstetric gynecologist prescribed the anti-inflammatory nimesulide $50 \mathrm{mg}$, the antibiotic cephalexin $500 \mathrm{mg}$ for 10 days, and an ultrasound examination (USG).

The result of the $1^{\text {st }}$ USG suggested the presence of two granulomas, one on the right side of the surgical scar, within the subcutaneous tissue, corresponding to a rounded, echogenic image, without Doppler flow, measuring $1.0 \times 0.9 \mathrm{~cm}$ and the other with the same characteristics, between the surgical and umbilical scar, located within the musculature, measuring $1.3 \times 0.8 \mathrm{~cm}$.

The gynecologist interpreted the results as a probable rejection of the unabsorbed sutures and advised the patient to look for the medical doctor responsible for performing the elective stitch removal surgery or waiting for the stiches to be completely absorbed.

The attending physician suggested an additional USG that showed an elongated hyperechoic area with a hypoechoic halo within the superficial muscular plane in the right pelvic region, which could correspond to a cicatricial fibrosis. The physician recommended waiting for the resorption of sutures in order to prevent the patient from undergoing another surgery.

According to the physician, multifilament synthetic absorbable thread was used in the aponeuroses. In the subcutaneous tissue, the suture was made with a simple

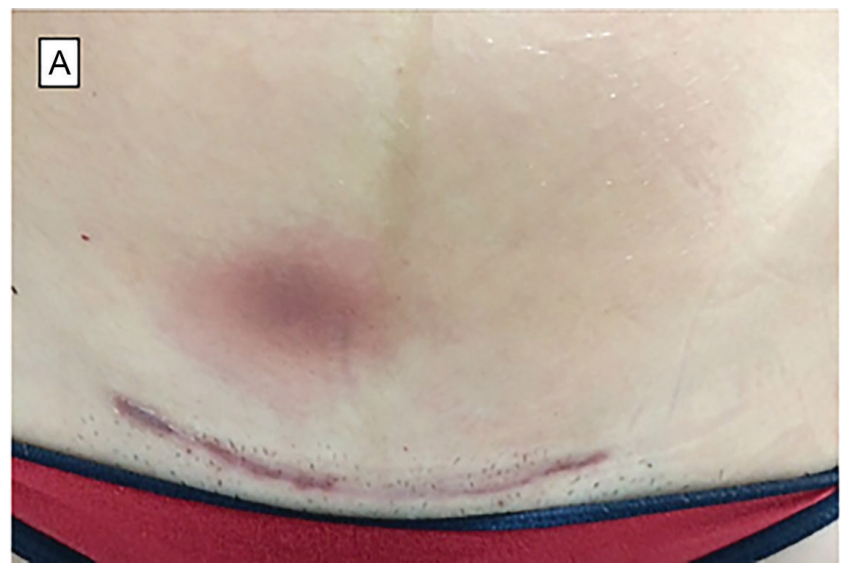

Cut-gut 0 multifilament natural absorbable thread, and in the skin a synthetic monofilament thread was used. However, after the end of drug treatment and before the wires were reabsorbed, the region began to show redness, intense pain and a greater hardening of palpation, as well as local burning (Figure 1A).

As conditions worsened, the patient sought gynecological help and had a $3^{\text {rd }}$ USG that observed a liquid, hypoechoic collection in the subcutaneous tissue forming a fistulous path towards the skin. There was also the presence of a hyperechogenic tubuliform halo adjacent to the liquid collection extending to the superficial muscular plane, measuring $3.2 \mathrm{~cm}$ in length and $0.6 \mathrm{~cm}$ in thickness, characterized as a fibrotic tissue.

Every time she stopped the anti-inflammatory drug, she had pain returned and she sought a gynecological help again. The doctor decided to make a small incision at the site and found the presence of a purulent exudate, suggesting an abscess. A drain was placed for 3 days, Ciprofloxacin $500 \mathrm{mg}$ for 10 days and Nimesulide $50 \mathrm{mg}$ for 5 days were prescribed. The incision made for drainage healed within 18 days (Figure 1B) as well as the right corner of the cesarean section.

However, 24 days after the drainage, she reported having the same symptoms, but this time on the left side, close to the navel. Finally, she turned to the doctor to discuss possible causes, including some type of allergic reaction to sutures, seroma or post-cesarean endometriosis. Considering that she had a problem related to healing, she was referred to a plastic surgeon and then to an infectious disease specialist due to a new amamnesis and the lack of response to treatment, possibly caused by a resistant microorganism.

After five months without an accurate diagnosis and after reviewing the tests performed, the infectious disease specialist told the patient that she had an infection most

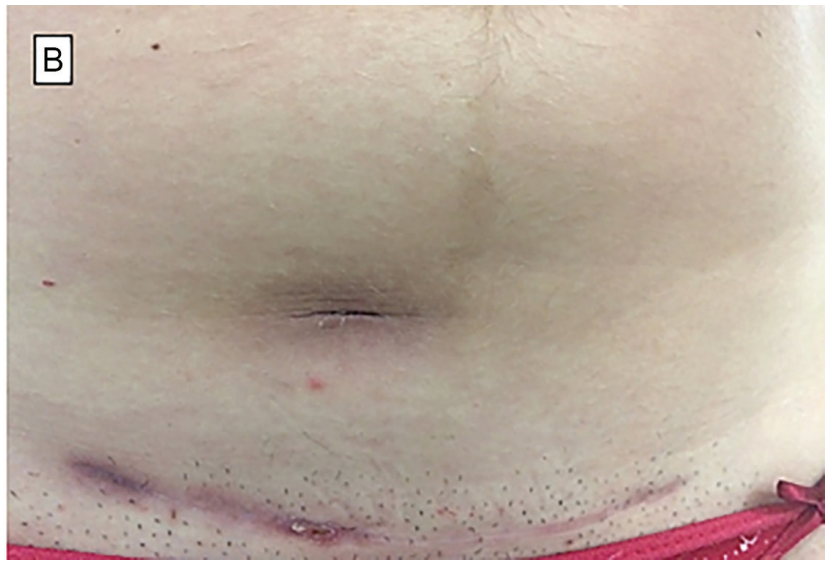

Figure 1 - A) Pelvis region, $4 \mathrm{~cm}$ above the cesarean section, right side of the alba line, showing a hyperemic area; B) Hyperemic area of the drainage incision, $4 \mathrm{~cm}$ above the cesarean section scar. 
likely due to FGM. During this time, more USG, blood and urine tests were performed to assess her renal and hepatic functions.

All blood and urine tests results were within normalranges. . Nonetheless, the new USG revealed that at the first drainage site there was a collection together with and inflammatory process and a fistulous tract that deepened to the muscular aponeurosis (Figure 2A). On the left of the alba line, there was a collection and a fistulous pathway that deepened to the muscular aponeurosis near the fistula reported previously, but without a deeper collection (Figure 2B).

Based on the clinical signs, recent USG data, and nonresponse to the conventional antibiotic therapy prescribed, an empirical treatment for FGM was started. To this end, $500 \mathrm{mg}$ of oral clarithromycin was prescribed every $12 \mathrm{~h}$ for a period of one year. Surgery was performed for debridement and sample collection (subcutaneous tissue for histopathology and exudate for culture). Amikacin 1g/dose three times a week intravenously was administered for a period of six months beginning on the day of surgery and periodically maintained at the IPD/UFPE.

The histopathological analysis of hematoxylineosin (HE)-stained tissue fragments revealed a chronic inflammatory process with the presence of tuberculoid granulomas composed of epithelioid cell clusters, surrounded by lymphocytes, permeated by neutrophils and occasionally by multinucleated giant cells (Figure 3). During the Ziehl-Nieelsen testing, no bacilli were identified. Microbiological tests were negative for both, bacterial and mycological cultures.

Because the culture did not show mycobacterial species, the paraffin-embedded tissues were extracted and underwent a real-time PCR at the Oswaldo Cruz/UFPE
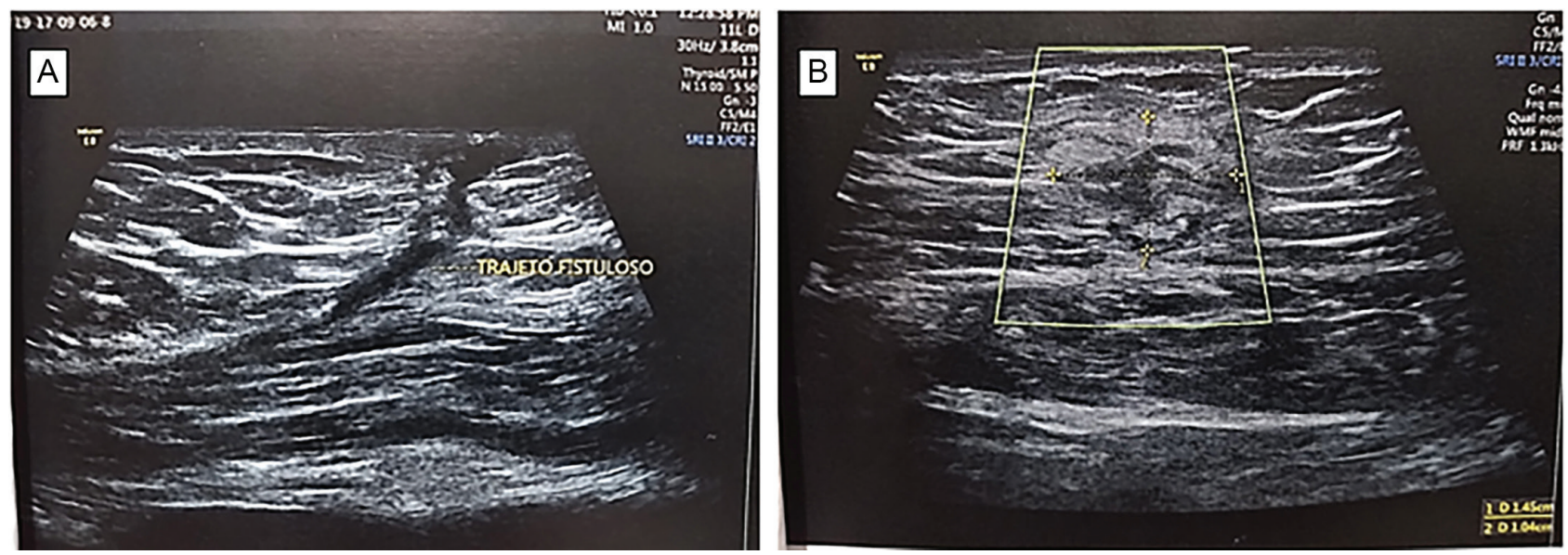

Figure 2 - A) Abdominal wall USG (hypogastric region) presenting with a collection and a fistulous path that deepens from the skin to the muscular aponeurosis; B) Abdominal wall USG (hypogastric region) presenting with a collection area in the second affected site.

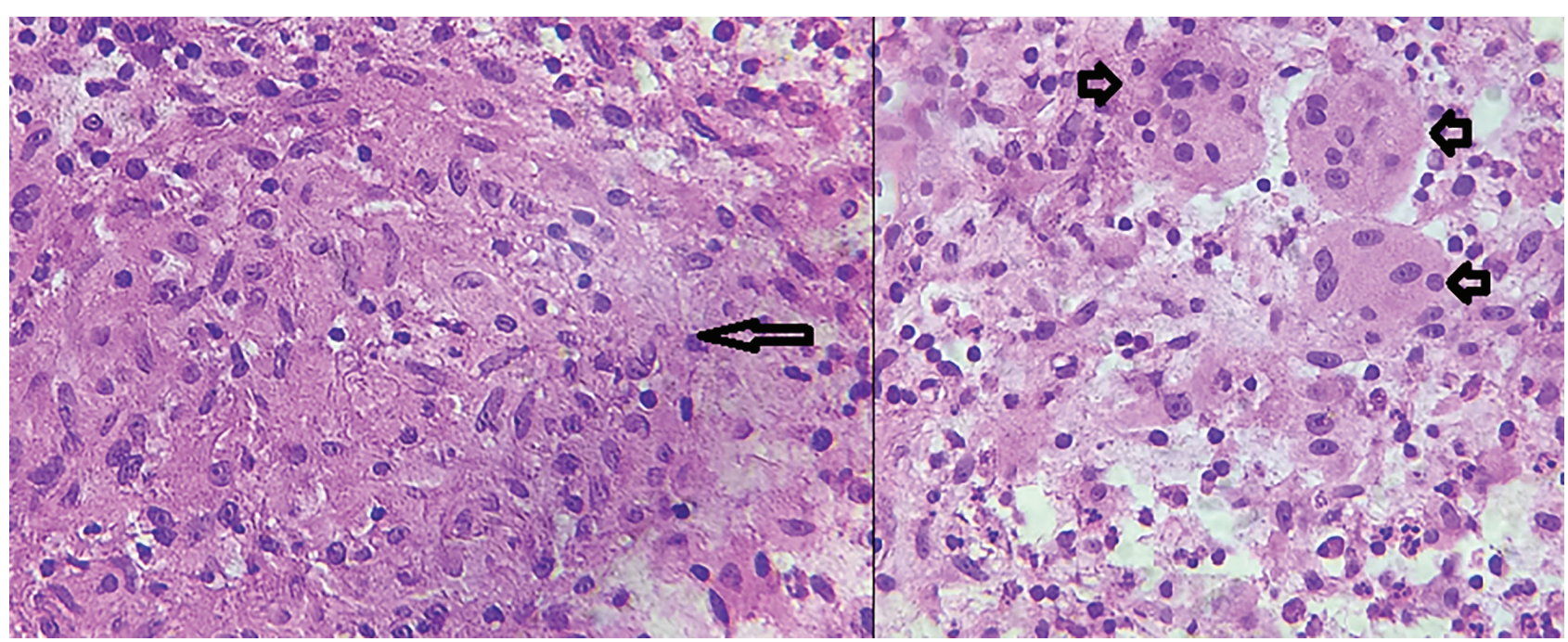

Figure 3 - Histopathological image of a subcutaneous tissue fragment showing a lymphocyte-permeated tuberculoid granuloma formed by epithelioid cells (long arrow) and occasional multinucleated giant cells (short arrows) (400 X magnification - HematoxylinEosin staining). 
Foundation's Aggeu Magalhaes-CPqAM Research Center's Immunoepidemiology Laboratory. The microorganism identified belonged to the species Micobacterium fortuitum.

During the combined antibiotic therapy with injectable amikacin and oral clarithromycin, the patient showed a considerable clinical improvement, without new foci or recurrences of hard nodules. After one month of treatment, the USG did not reveal the presence of new collections or fistulas in the subcutaneous tissue. By the $4^{\text {th }}$ month of treatment, fistulas were closing and the patient reported skin hypersentivity on the affected region, as well as mild pain.

After six months, amikacin was discontinued, but clarithromycin continued for a year. During the six months of combined treatment, blood and urine tests revealed no changes. However, the audiometry testing performed at the beginning and at the end of treatment showed a slight loss of hearing. The patient reported that after the $4^{\text {th }}$ month of treatment she started to have sporadic tinnitus in ears. After the end of the combined therapy, the patient continued without relapses and the last two USG found no collections but showed the healing of fistulas. The patient will remain under observation for another year.

\section{DISCUSSION}

Diseases caused by FGM on skin or soft tissues usually present with signs and symptoms of inflammation. The incubation period may vary from one week to two years ${ }^{6}$. Fever is rare and drainage may be purulent, usually odorless and colorless, resembling a sterile seroma. Patients do not respond to conventional antibiotic therapy, leading to delayed diagnoses ${ }^{7}$.

FGM are capable of biofilm formation directly linked to a greater persistence of these pathogens in the environment ${ }^{8}$. The species are commonly found in nosocomial skin and soft tissue infections, mainly in aesthetic procedures ${ }^{3,9}$. This explains why the plastic surgeon suspected a resistant microorganism infection and referred the patient to an infectious disease specialist.

Infections caused by FGM are not considered a public health problem. Therefore, their reporting is not mandatory, although some species are highly pathogenic and are responsible for diseases and deaths ${ }^{10}$. FGM infections have emerged as an important cause of hospital-acquired surgical site infection causing great morbidity and mortality. They are poorly described in the literature in cesarean sections and in clinical practice, being commonly associated to surgical site infections ${ }^{11}$. These factors may have contributed to a lengthy diagnosis.

It was not possible to trace the source of the infection. FGMs do not easily penetrate the host tissues, and that is why they are related to post-trauma infections or after invasive procedures. These bacteria can survive and reproduce over a broad spectrum of $\mathrm{pH}$, temperature, salinity and oxygen availability. In addition, many FGMs do not respond well to routinely used disinfectants ${ }^{12}$.

The pathogenesis of FGM is mediated by T lymphocytes. Their spread is usually due to immune system deficiencies associated to reduced levels of interleukin-12 and interferon-gamma ${ }^{13}$. The patient was HIV-negative and her leukocyte parameters were normal. However, during pregnancy there are many hormonal and steroids changes modulating the immune response. Several studies have shown that suppression of the immunocellular system occurs during pregnancy to prevent fetal rejection by increasing estrogen and/or progesterone levels, especially the latter which increases the synthesis of proinflammatory cytokines ${ }^{14}$. Therefore, it is suggested that the gestational and post-gestational period may have made the patient temporarily more susceptible.

In clinical practice of gynecology and obstetrics, absorbable and nonabsorbable, monofilament and multifilament sutures are used. Cutgut thread can cause many tissue reactions and have an unpredictable absorption time ${ }^{15}$. As sutures were not found, it was not possible to prove that they were the source of the infection.

Even with negative results from the main form of diagnosis, a patient who underwent invasive procedures and presents with two or more signs of a compatible symptomatology such as hyperemia, edema for more than a week, hard to heal erythematous lesions, nodular lesions with or without secretion drainage, fistulas, ulcerations, hot or cold abscess, non-response to conventional antimicrobial treatments should begin FGM-specific antimicrobials. Except for hyperemia, the patient in question presented with all clinical signs referred by the National Health Surveillance Agency (ANVISA)technical note ${ }^{5}$ and only responded to specific treatment for fast-growing mycobacteria.

The time between the collection of material (exudate) and the arrival at the laboratory, at room temperature, should not exceed one hour for the culture of FGM. If a longer time is required, the sample should be transported in a Styrofoam container, insulated in a plastic bag, kept refrigerated at 2-8 ${ }^{\circ} \mathrm{C}$ for up to $72 \mathrm{~h}^{16}$. The sample (exudate) was only taken to the lab $5 \mathrm{~h}$ after collection in an ice bag and this may have compromised the viability of FGM.

USG, magnetic resonance imaging, tomography and histopathological exams are the most recommended tools for diagnosis of FGM. Regarding the therapeutic scheme, it should include surgery for debridement and antibiotic therapy ${ }^{5,16}$. In case of negative cultures, but with the presence 
of granulomas in the histopathological examination, the patient should be prescribed clarithromycin for six months and amikacin three times a week for 1-2 months, that may be extended up to six months.

The histopathological findings caused by FGM are chronic granulomatous inflammatory lesions and necrotizing granulomas with epithelioid cells, histiocytes and giant cells ${ }^{5}$. Because it fit the histopathological conditions described above, as well as presenting withhyperemia, hyperthemia, fistulas, collection and more than one lesion, even being immunocompetent, we opted for the extended treatment for this patient.

Molecular examinations, such as RT-PCR, are another option for identifying FGM species and differentiating them from the Mycobacterium tuberculosis complex ${ }^{17}$ and in the case of this patient, the species was only identified using this method.

Treatment for FGM is often complicated due to the side effects of antibiotic therapy, especially the amikacin ototoxicity ${ }^{18}$. Normally, aminoglycosides predominantly affect a portion of the inner ear, the cochlear and labyrinth hair cells, which may cause permanent hearing loss or tinnitus secondary to the degeneration of cochlear sensory hair cells. There may also be dizziness or imbalance as a result of damage to the sensory structures of the vestibular system ${ }^{19}$. According to the audiometry exams, the patient had no significant hearing loss, just sporadic tinnitus.

The most important aspect in mycobacterial infections is their prevention. There is need for a rigorous care in cleaning and sterilizing material after surgical procedures. $M$. fortuitum and $M$. chelonae strains are resistant to various disinfectants, including polyvinylpyrolidone (PVPI), formaldehyde and glutaraldehyde ${ }^{5}$.

\section{CONCLUSION}

It is of extreme importance to share these occurrences with gynecological-obstetric specialists. A multidisciplinary team can assist in a faster and more accurate diagnosis, saving the patient from prolonged suffering in both psychological and pathophysiological aspects related to the toxicity of long-term medications.

\section{AUTHORS' CONTRIBUTIONS}

CSM: histopathological analysis, proposed the publication of the case, manuscript writing; PSRA: participate in diagnostic and treatment; HCS: participate in diagnostic; JPS: participate in surgery; ASC: did the ultrasound scan; JRAQJ: manuscript writing and editing; FCAMT: proposed the publication of the case;
JPM: histopathological analysis; BMT: proposed the publication of the case; GESM: manuscript writing; RVS A: histopathological analysis; SLMH: participate in diagnostic and treatment.

\section{CONFLICT OF INTERESTS}

The authors declare that they have no conflict of interests.

\section{ETHICAL APPROVAL}

Data collection was carried out after approval by the Research Ethics Committee of the Federal University of Pernambuco, observing the established norms by the resolution 466/12, of the National Health Council, which describes the research involving Human Beings, $\mathrm{N}^{\circ} 2376-$ 019498/2019-71.

\section{REFERENCES}

1. Duarte RS, Lourenço MC, Fonseca LS, Leão SC, Amorim EL, Rocha IL, et al. Epidemic of postsurgical infections caused by Mycobacterium massiliense. J Clin Microbiol. 2009;47:214955 .

2. Cowman S, Wilson R, Loebinger MR. Opportunistic mycobacterial diseases. Medicine. 2016;44:390-2.

3. Zhang X, Liu W, Liu W, Jiang H, Zong W, Zhang G, et al. Cutaneous infections caused by rapidly growing mycobacteria: case reports and review of clinical and laboratory aspects. Acta Derm Venerol. 2015;95:985-9.

4. Santos DR, Lourenço MC, Coelho FS, Mello FC, Duarte RS. Resistance profile of strains of Mycobacterium fortuitum isolated from clinical specimens. J Bras Pneumol. 2016;42:299301.

5. Brasil. Ministério da Saúde. Agência Nacional de Vigilância Sanitária. Nota técnica conjunta No 01/2009 - SVS/MS e ANVISA. Assunto: infecções por micobactérias de crescimento rápido: fluxo de notificações, diagnósticos clínicos, microbiológico e tratamento. Brasília: Ministério da Saúde; 2009. [cited 2021 Mar 25]. Available from: https:// www.ribeiraopreto.sp.gov.br/files/ssaude/pdf/ci-notatecnicaconjunta-012009-svsms-anvisa.pdf

6. Griffith DE, Aksamit T, Brown-Elliott BA, Catanzaro A, Daley C, Gordin F, et al. An official ATS/IDSA statement: diagnosis, treatment, and prevention of nontuberculous mycobacterial diseases. Am J Respir Crit Care Med. 2007;175:367-416.

7. Kannaiyan K, Ragunathan L, Sakthivel S, Sasidar AR, Muralidaran, Venkatachalam GK. Surgical site infections due to rapidly growing mycobacteria in Puducherry, India. J Clin Diagn Res. 2015;9:DC05-8. 
8. Gomez-Alvarez V, Revetta RP. Whole-genome sequences of four strains closely related to members of the Mycobacterium chelonae group, isolated from biofilms in a drinking water distribution system simulator. Genome Announc. 2016;4:e01539-15.

9. Singh M, Dugdale CM, Solomon IH, Huang A, Montgomery MW, Pomahac B, et al. Rapid-growing mycobacteria infections in medical tourists: our experience and literature review. Aesthet Surg J. 2016;36:NP246-53.

10. Weiss CH, Glassroth J. Pulmonary disease caused by nontuberculous mycobacteria. Expert Rev Respir Med. 2012;6:597-612.

11. Smith GS, Ghio AJ, Stout JE, Messier KP, Hudgens EE, Murphy MS, et al. Epidemiology of nontuberculous mycobacteria isolations among central North Carolina residents, 2006-2010. J Infect. 2016;72:678-86.

12. Girgis DO, Karp CL, Miller D. Ocular infections caused by non-tuberculous mycobacteria: update on epidemiology and management: ocular mycobacterial infections. Clin Exp Ophthalmol. 2012;40:467-75.

13. Wu UI, Holland SM. Host susceptibility to non-tuberculous mycobacterial infections. Lancet Infect Dis. 2015;15:968-80.

14. Jain SK, Kannan K, Prouty L, Jain SK. Progesterone, but not $17 \beta$-estradiol, increases TNF- $\alpha$ secretion in U937 monocytes. Cytokine. 2004;26:102-5.
15. García-Osogobio SM, Takahashi-Monroy T, Velasco L, Gaxiola M, Sotres-Vega A, Santillán-Doherty P. Anastomosis colónicas en una sola capa continua con poligliconato (maxon) vs. anastomosis en dos capas con catgut crómico y seda. Estudio experimental. Rev Invest Clin. 2006;58:198-203.

16. Cai SS, Chopra K, Lifchez SD. Management of Mycobacterium abscessus infection after medical tourism in cosmetic surgery and a review of literature. Ann Plast Surg. 2016;77:678-82.

17. Taylor TB, Patterson C, Hale Y, Safranek WW. Routine use of PCR-restriction fragment length polymorphism analysis for identification of mycobacteria growing in liquid media. J Clin Microbiol. 1997;35:79-85.

18. Vasconcelos KA, Frota SM, Ruffino-Netto A, Kritski AL. Sequential analysis as a tool for detection of amikacin ototoxicity in the treatment of multidrug-resistant tuberculosis. J Bras Pneumol. 2018;44:85-92.

19. Peloquin CA, Berning SE, Nitta AT, Simone PM, Goble M, Huitt GA, et al. Aminoglycoside toxicity: daily versus thrice-weekly dosing for treatment of mycobacterial diseases. Clin Infect Dis. 2004;38:1538-44. 